\title{
Testosterone and Economic Risk Taking: A Review
}

\author{
Coren L. Apicella • Justin M. Carré • Anna Dreber
}

Received: 21 September 2014 /Revised: 8 December 2014 / Accepted: 11 December 2014 / Published online: 6 January 2015

C Springer International Publishing 2014

\begin{abstract}
Since precise forecasting of the future is not possible, most of life's decisions are made with uncertain outcomes. One important facet of uncertainty that is of particular interest to decision scientists is risk - the choice between an option that is less rewarding but more certain and an option that is less certain, but potentially more rewarding. Recent developments in both neuroscience and behavioral endocrinology have helped to reveal the biological mechanisms that support decision-making involving economic risk, and consequently, potential factors associated with individual differences in risk taking. This review is dedicated to surveying recent developments that link the hormone testosterone to economic risk taking. Like neuroeconomics, endocrinological approaches may provide a potentially powerful framework from which to understand decision-making and may help to make sense of a number of well-documented behavioral anomalies involving economic risk. Specifically, we suggest that testosterone functions to modulate risky behaviors in ways that appear to be adaptive. Still, more work is needed to understand the nature of the relationship between testosterone and risk in both sexes.
\end{abstract}

Keywords Economic risk taking · Financial decision-making $\cdot$ Testosterone $\cdot 2 \mathrm{D}: 4 \mathrm{D}$

\section{Introduction}

Possibly casinos understand best that humans do not always make decisions that maximize expected value - global revenues for the casino gaming industry presently

C. L. Apicella $(\square)$

Department of Psychology, University of Pennsylvania, 3720 Walnut Street, Philadelphia, PA 19104, USA

e-mail: capicella@psych.upenn.edu

J. M. Carré

Department of Psychology, Nipissing University, North Bay, ON, Canada

e-mail: justinca@nipissingu.ca

\section{A. Dreber}

Department of Economics, Stockholm School of Economics, P.O. Box 6501, 11383 Stockholm, Sweden

e-mail: anna.dreber@hhs.se 
stand at over 100 billion USD (PricewaterhouseCoopers 2010). To explain this departure from expected value economists often rely on models of choice behavior that account for the subjective value or "utility" of options. The dominant model, first proposed in 1738 by Daniel Bernouli, is called expected utility. These models, where individuals are assumed to choose the alternative that maximizes their expected utility, ${ }^{1}$ provide a compelling, yet simple, framework for understanding how individuals make decisions under risk and uncertainty. Nevertheless, systematic violations of expected utility are widespread (see Starmer 2000 for review). Other models, such as loss aversion, where probabilities themselves are weighted (Kahneman and Tversky 1979) have accounted for some of these violations, but they too fail to explain other behaviors such as avoiding outcomes that, while tragic, are extremely rare (Loewenstein et al. 2001). The last 15 years has witnessed further refinements of choice models as our understanding of decision-making has become more sophisticated and complex. Concomitantly, a break from the traditional view that preferences can only be revealed through choice has led to more research about the psychological and biological foundations of economic risk taking. Though still incomplete, we have a better understanding of individual differences in economic risk taking including preference shifts within individuals and the reciprocal interactions between choice, outcome and biology.

This review focuses on the steroid hormone testosterone as a potential mediator of financial decision-making involving risk. While there is great value in understanding the neural substrates involved in economic decision-making, less attention has been given to the role of hormones. One possible reason for this difference in focus is that human cognition and decision-making is sophisticated and necessitates higher order brain mechanisms. However, the corollary of this is that since behavior and decisions are more cognitively driven they should be largely decoupled from the effects of hormones (Bos et al. 2012a, b). While it is true that simple one-directional hormonebehavior relationships are either rare or non-existent in humans, there is still mounting evidence suggesting that hormones causally contribute to a wide range of behavioral propensities (see Bos et al. 2012a, b). Moreover, there is concrete evidence that steroid hormones do act on the brain via genomic and non-genomic pathways (for review see Höfer et al. 2013). For instance, testosterone regulates gene expression in the brain by binding to androgen receptors (AR). It also acts as a neuroactive steroid by modulating neural excitability through its interaction with ligand-gated ion channels (for review see Do Rego et al. 2009). Even more, testosterone can affect the brain indirectly through its conversion to estradiol by aromatase (for review see Rahman and Christian 2007). And estradiol also has a number of important and functionally distinct genomic and nongenomic effects on the brain. Finally, testosterone and estradiol can mediate the synthesis of neuropeptides, including vasopressin and oxytocin, in a number of brain regions. For these reasons, we believe it is still an open and important empirical question as to whether and how much hormones govern human economic decisionmaking. Such research not only allows for a richer understanding of hormone-behavior relationships, but also has the potential to inform traditional neuroeconomic approaches to the study of brain-behavior relationships.

\footnotetext{
${ }^{1} E V=\left(U^{*} P\right)$ where $U$ is the vector of subjective values assigned to possible outcomes, and $P$ is vector of the probabilities that each outcome will occur.
} 


\section{Risk Preferences}

Economic risk preferences are defined by the tradeoff between the variance and the expected value for a given resource. To illustrate this, imagine a lottery that gives a $50 \%$ chance of winning $\$ 100$ and a $50 \%$ chance of winning $\$ 0$, with the expected value thus being $\$ 50$. If an individual is indifferent between receiving $\$ 50$ with certainty or trying their luck at this lottery, the individual is considered to be risk neutral. If an individual prefers the gamble to the certain outcome of $\$ 50$, they are considered to be risk loving, whereas if they prefer the certain $\$ 50$ to the lottery, they are considered to be risk averse. While this specific illustration involves money, many decisions in life entail elements of risk. Moreover, many of those decisions, whether about parenting, mating or foraging, can have real fitness consequences.

Examples in the animal kingdom of species choosing between more certain, but potentially less rewarding outcomes versus less certain but more rewarding outcomes, are plentiful. Maternal cannibalism is fairly rare in the animal kingdom but does occur in some species. On the surface the behavior presents as a Darwinian conundrum: Why would a mother ever choose to cull her own biological offspring? In some species, such as the golden hamster, this behavior has been explained as a risk management strategy (Day and Galef 1977). That is, mothers eliminate pups from their litter in order increase the probability that the remaining pups will survive, leading to less variance in outcomes. In other species, behavioral decisions under the threat of predation are common. For instance, males of many species emit mating calls in order to attract females. Unfortunately for some males, such as the tungara frog, these calls also alert potential predators to their whereabouts (for review see Magnhagen 1991). Thus by emitting louder or more frequent calls males are increasing risk, since they are both more likely to attract mates and attract predators. In extant hunter-gatherers and presumably our ancestors, decisions are made daily as to which foods to target for consumption. Some foods, such as meat, are abundant in calories and nutrients but are more risky to obtain compared to other items that, while more reliably procured, provide less energy and nutrition. And while investment portfolio selections provide a current and obvious example of decision-making involving risk, almost every domain of modern life involves similar choice types. These can include weighty decisions, such as the choice between different career paths or medical treatments and more mundane decisions, such as when to fold in poker games.

Since risk is a central feature of decision-making common to many animals and a feature of behavior not without fitness consequence, economic risk preferences may have biological substrates. Interestingly, violations of standard utility theory, including choices involving risk and uncertainty, have also been documented in other animals (see Kagel 1995). As a result, some economists have grappled with understanding the evolutionary origins of preference formation. For instance, some have examined how selection may have favored risk taking in some environments such as winner-takes-all tournaments (Dekel and Scotchmer 1999), while others have examined the origins of sex differences in risk taking (Robson 1996). Others still, assume preferences are exogenous and have asked why agents have preferences at all (Robson 2001; Samuelson and Swinkels 2006)? In other words, why did selection favor utility functions rather than having organisms attach utilities to items directly comparable to the fitness benefits they provide? Currently there are two main complementary 
evolutionary accounts for utility functions. Robson (2001) suggests that preferences provide agents with increased flexibility so that organisms can cope with novel and changing environments, while Samuelson and Swinkels (2006) suggest that having intermediate preferences results in better decision-making in environments with imperfect information. While little is known about the ultimate origins of risk preferences, research examining the heritability of economic decision-making, including risk, ${ }^{2}$ provides some evidence that these decisions are influenced by genes and, at the very least, subject to selection (Cesarini et al. 2010).

In economics it is often assumed that preferences are exogenous and stable. However, there is substantial variation in risk preferences between individuals (e.g. Dohmen et al. 2011). Moreover, while relatively stable individual differences exist, risk preferences are also flexible, with the most extreme case being preference reversal (Tversky et al. 1990). When exploring incentivized gambles involving risk, it is common to see that demographic variables such as age, sex, education and socioeconomic status can account for some of the variation in risk taking (e.g. Barsky et al. 1997; Dohmen et al. 2011). For example, it is often found that women and older individuals are, on average, less risk taking than men and younger individuals, though the effect sizes are often fairly small (see Nelson 2012 for sex differences in risk taking). Also, using lab measures and financial market data, variation in risk preferences have also been associated with situational contexts and previous economic experience. For example, girls randomly put in same-sex groups are more risk taking than girls in mixed-sex groups (Booth and Nolen 2012), and growing up under times of low economic growth and high inflation correlates with low risk taking as an adult (Malmendier and Nagel 2011). Finally, there is also evidence suggesting that men become more financially risk taking following physical contact with a woman (Levav and Argo 2010). While many of these findings provide interesting and important insights into understanding individual differences in decision-making, much of the variation in economic risk taking remains elusive (Camerer 2003). Moreover, none of these findings individually or collectively provide a comprehensive and theoretically compelling explanation for understanding risk and decision-making. As a result, researchers have increasingly relied on insights and methodologies from psychology and biology to help develop a more complete economic science. For example, an emerging body of work has set out to explain individual variation in risk taking with psychological variables, such as moods and/or emotions (Loewenstein et al. 2001), biological variables, such as genetic polymorphisms (e.g. Dreber et al. 2009; Kuhnen and Chiao 2009, though see Benjamin et al. 2012 for a discussion of problems with this research) and brain activation (e.g. Kuhnen and Knutson 2005; Platt and Huettel 2008). Others have examined the role of hormones on financial risk.

\section{Testosterone}

With advancements in non-invasive hormonal sampling, behavioral endocrinology research has been catapulted into nearly every domain of the social sciences including

\footnotetext{
${ }^{2}$ This study examined individual investment decisions among twins in the Swedish Twin Registry and found that genetic variation accounted for approximately $25 \%$ of variation in portfolio risk.
} 
anthropology (e.g. Ellison et al. 2002), primatology (e.g. Muller and Wrangham 2004), politics (e.g. Apicella and Cesarini 2011), management (Sapienza et al. 2009) and economics (e.g. Apicella et al. 2008, 2014). One hormone that has received substantial attention in relation to risk taking is the steroid hormone testosterone.

Testosterone is a steroid hormone mainly produced by the testes in men, but it is also present in women in smaller quantities. Specifically, testosterone is produced in both the ovaries and adrenal glands in roughly equal quantities totaling an amount that is approximately $1 / 8$ of the amount of testosterone typically found in men. Testosterone plays an important role for reproductive physiology and development and modulates a number of behavioral processes of relevance to survival and reproduction, especially in males (Adkins-Regan 2005; Dixson 1998; Nelson 2005; Wingfield et al. 1990). In several species, including humans, testosterone has been linked to aggression (Archer 2006), sensation seeking (see Roberti 2004 for a review), hostility (Hartgens and Kuipers 2004), food acquisition (Worthman and Konner 1987), mate-seeking (Roney et al. 2007), and dominance in males (Mazur and Booth 1998).

Studies of association are typically the first step in understanding the relationship between hormones and behavior. While a useful and pragmatic first step, it is important to recognize that the usual concerns of causality may apply with more force to the field of behavioral endocrinology where reciprocal causality is common. For instance, a growing literature suggests that while testosterone may influence aggression, aggressive behaviors or actions can also be associated with a rise in testosterone (Carré and McCormick 2008a). A potential further complication is that hormones, like testosterone, can affect behavior both through organizational and activational effects (Beatty 1979). That is, critical periods of exposure to testosterone can permanently influence behavior and affect the way in which individuals respond to the activating or nonpermanent effects of testosterone over the lifespan. These critical periods of exposure are thought to take place during key developmental stages such as fetal development and puberty.

Recently researchers have set out to examine whether testosterone may play a role in economic risk taking. The involvement of testosterone was suspected for a few reasons. As mentioned, testosterone had previously been linked to a number of activities that involve elements of risk in both humans and other animals. For instance, the competitive and risky behaviors observed in males of many species are often activated by testosterone during the breeding season (Balthazart 1983; Harding 1981; Wingfield et al. 1990). Moreover, the documented sex difference in economic risk taking as well as the decline in economic risk taking with advancing age are both findings that accord with testosterone as a potential mediator. Testosterone concentrations are not only higher in men relative to women (Dabbs 1990) but also decrease steadily with age in industrialized populations (Kaufman and Vermeulen 2005).

Here we describe the nascent literature on testosterone and economic risk taking, potential shortfalls and ways forward for future research. ${ }^{3}$ Our review includes measures of economic risk preferences, where probabilities are known and measures mainly incentivized, but related measures and constructs are briefly discussed in a specific subsection.

\footnotetext{
${ }^{3}$ See Hoffman et al. (2014) for related work.
} 


\section{Economic Risk Preferences and Testosterone}

The literature on testosterone and economic risk preferences is small and relatively novel. Below we present the papers in chronological order, starting with those that only look at correlations and then addressing those where testosterone is administered. We finish by discussing potential organizational effects of testosterone on financial risk taking.

\section{Endogenous Testosterone}

The first study to directly relate testosterone to risk taking is Apicella et al. (2008). In a study involving 95 males aged 18-23, they find that circulating levels of testosterone correlate positively with risk taking in an investment task. Risk taking is measured from a single incentivized choice, where participants receive $\$ 250$ on their "account" and can choose to invest any amount X between 0 and 250 into a risky investment that succeeds with $50 \%$ probability and fails with $50 \%$ probability. If the investment succeeds, the amount invested is multiplied by 2.5 and returned to the participant, resulting in $\$ 250+1.5 \mathrm{X}$ on the account. If the investment fails, the amount invested is lost, resulting in $\$ 250-\mathrm{X}$ on the account. Regardless of outcome, participants keep all the money that was not invested 250-X. This measure is based on Gneezy and Potters (1997). In the end, one participant was randomly drawn, the investment's outcome was determined, and this one participant was paid according to the balance on his account. The results from Apicella et al. (2008) suggest that a man with a testosterone level one standard deviation above the mean invests $12 \%$ more than a man with an average testosterone level.

Sapienza et al. (2009) look at a sample of 460 MBA students (320 men, 140 women). While they fail to replicate the result of Apicella et al. (2008) in the full sample of men, they find that among women testosterone correlates positively with risk taking. However, when Sapienza et al. (2009) restrict the sample to individuals with relatively low concentrations of testosterone $(90 \%$ of the women and $31 \%$ of the men in the sample), they find that within-gender testosterone is positively linked to risk taking. Risk taking in this paper is measured from 15 incentivized choices were participants chose between a gamble that gives either $\$ 200$ or $\$ 0$ with equal probability or a certain amount that varied in increasing order from $\$ 50$ to $\$ 120$ in increments of $\$ 5$. Risk preferences are measured from the point at which participants choose to switch from preferring the gamble to the certain amount. Participants were paid for one randomly picked choice.

Stanton et al. (2011b) look at the correlation between testosterone and risk taking in a sample of 298 participants (142 men, 156 women). They find evidence of a non-linear relationship, suggesting that low and high testosterone individuals take more risk than other individuals. This relationship is also found among both men and women when the two groups are analyzed separately. Participants here make 120 incentivized choices between a certain amount (varying in increments of $\$ 1$ from $\$ 3$ to $\$ 7$ ) and a gamble (where the probability of winning is 25,50 or $75 \%$ ), such that the expected value of the gamble is mainly larger than the value of the certain amount. Participants also make choices related to ambiguity 
preferences and loss aversion. Stanton et al. (2011b) similarly find a non-linear relationship between testosterone and ambiguity preferences, but no relationship with loss aversion. ${ }^{4}$

Schipper (2012) explores the relationship between testosterone and risk preferences in a sample of 208 participants (115 men, 93 women). ${ }^{5}$ He has participants make ten different choices between pairs of incentivized gambles (as in Holt and Laury 2002) in both the gain and the loss domain, where the probabilities of winning or losing vary from 10 to $100 \%$. Risk preferences are inferred from the switching point when people start preferring riskier gambles over safer gambles (one set of gambles involve amounts that either are $\$ 3.20$ or $\$ 4$ whereas the other set of gambles involve amounts that are either $\$ 0.20$ or $\$ 7.70$ ). Participants were paid for one randomly picked choice for each of the gains and losses tasks. Schipper finds a positive relationship between testosterone and risk taking for men in the domain of gains but not losses. For women, no relationship between testosterone and risk is found in either the loss or gain domain. Schipper also studies other hormones (cortisol, estradiol and progesterone) and finds a negative association between cortisol and risk taking in women but not in men.

Notably, testosterone concentrations are not static, but rather, fluctuate over both long-term (e.g., during the season and with aging) and short-term scales (e.g., through the day and in response to social interactions). Thus, in addition to focusing on individual differences in baseline testosterone concentrations, a growing body of evidence suggests that context dependent changes in testosterone concentrations may serve to adaptively modulate ongoing and/or future social behavior (see Carré et al. 2011 for review). Specifically, it has been found that acute changes in testosterone during competition predict subsequent competitive motivation (Mehta and Josephs 2006; Carré and McCormick 2008a), in-group support (Apicella and Cesarini 2011), aggression (Carré et al. 2009; Carré et al. 2013; Carré et al. 2014a), antagonistic behavior (Geniole et al. 2013), ratings of trust from emotionally neutral faces (Carré et al. 2014b) and mate-seeking behavior (Roney et al. 2007; van der Meij et al. 2012). Three recent studies have investigated links between context dependent changes in testosterone concentrations and risk taking behavior in men and women.

Carney et al. (2010) study whether randomizing participants to either low-power or high-power poses can affect hormonal levels and risk taking. In a sample of 42 participants (16 men, 26 women), they find that participants in high-power poses have increased testosterone, decreased cortisol and increased risk taking compared to participants in low-power poses. ${ }^{6}$ However, it is unclear whether individual differences in testosterone responses mediated the effect of power posing on risk taking. High-power poses also lead to more powerful feelings and lower cortisol. Risk taking is here measured from a single incentivized choice between a certain

\footnotetext{
${ }^{4}$ Ambiguity aversion and risk aversion are related concepts but ambiguity aversion refers to a preference for known risks (e.g. probabilities) over unknown risks..

${ }^{5}$ Note that the sample size is often smaller than this in the actual analyses.

${ }^{6}$ Note that this design has been subject to some discussion. Carney et al. collapse raw hormone data across sexes in their measures of hormonal change, without reporting pre- and post- mean testosterone levels separately for men and women, just the aggregate change. Stanton (2011) argues that this makes the data difficult to evaluate.
} 
amount (\$2) and a 50-50 gamble with the same expected value (with the outcomes of $\$ 4$ or $\$ 0)$.

Ranehill et al. (2014), using a sample of 200 participants (102 men, 98 women), perform a conceptual replication of Carney et al. (2010). As Carney et al., they find that high-power poses increase feelings of power. Unlike Carney et al., however, they find no effect on testosterone or risk taking in the domain of gains, in neither the overall sample or separately by sex. Ranehill et al. (2014) also explore risk taking in the domain of losses and competitiveness as willingness to compete when solving a task. They find no effect of high-power poses on any of these outcome measures or on cortisol. The risk task in the gain domain consists of six choices between a certain amount in Swiss Francs (CHF 2 to CHF 7, varying in increments of CHF 1) and a 50-50 gamble (with outcomes CHF 10 or CHF 0), with risk preferences measured from the share of risky choices given. Risk preferences in the loss domain are inferred correspondingly with amounts being lost rather than gained. Participants where paid for one of the risky decisions, randomly picked.

In other recent work, Apicella et al. (2014) examine how changes in testosterone following monetary wins and losses influence future financial risk taking. The researchers collect saliva samples from men before and after they either won or lost a series of chance-based competition (e.g. 15 trials of rock, paper, scissors), where money is at stake. The amount of money at stake varies across conditions so that direct comparisons can be made between winners and losers whose final earnings are the same. Thus, the final sample includes 49 men who either won or lost but finished the game with $\$ 10$. The risk task used is similar to that used by Ranehill et al. (2014). Participants make ten choices between a certain amount (varying from $\$ 1$ to $\$ 10$ in increments of $\$ 1$ ) and a 50-50 gamble (with outcomes $\$ 10$ or $\$ 0$ ), with one decision randomly picked for payment. The authors find that testosterone increased more in winners relative to losers, though the difference was not significant. Importantly, testosterone change from before to after the competition is positively correlated with monetary risk taking. It is important to note that this result remains after controlling for the outcome of the competition, suggesting that individual differences in testosterone reactivity influence future economic risk taking, rather than winning or losing.

To summarize, the literature on the bivariate relationship between endogenous testosterone and risk preferences suggest that higher levels of testosterone are associated with increased financial risk taking. However, the results have not been consistently found for both sexes and for all measures of risk. Furthermore, one study finds a non-linear association between testosterone and risk so that those with lower as well as higher levels of testosterone are more risk taking. Taken together, it is clear that more work is needed.

\section{Testosterone Manipulations}

We are aware of only two experiments that have examined the causal influence of testosterone on risk preferences. Neither study has found an effect. Zethraeus et al. (2009) administer testosterone (40 mg/day), estradiol ( $2 \mathrm{mg} /$ day) or a placebo to a sample of 200 post-menopausal women during a four-week period (testosterone: $n=$ 
67, estradiol: $n=66$, placebo: $n=67$ ). Participants choose between six different certain payoffs (SEK 80, 120, 160, 200, 240 and 300) and a 50-50 gamble (with the outcomes SEK 400 or SEK 0), with one choice randomly chosen for payment. As in Sapienza et al. (2009), risk preferences are measured from the point at which participants choose to switch from preferring the gamble to the certain amount. Compared to placebo, no effect of either testosterone or estradiol on risk preferences is observed.

Boksem et al. (2014) instead administer either testosterone $(0.5 \mathrm{mg}$ sublingually at one occasion) or placebo to a sample of 54 women aged 18-30 taking oral contraceptives. As in Zethraeus et al. (2009), there is no effect of testosterone on risk preferences (or on ambiguity preferences, but unlike Zethraeus et al. (2009) they find an effect on trust and reciprocal behavior measured from the investment game). The risk task here involves 18 choices where participants choose between a certain payoff (ranging from $€ 1.50$ to $€ 28.50$ ) and a 50-50 gamble (with the outcomes $€ 30$ or $€ 0$ ), with one choice randomly chosen to be paid out. Risk preferences are inferred by the share of gambles chosen.

In summary, the testosterone administration studies summarized do not provide compelling support for the causal role of testosterone in the modulation of risk preferences. However, it is important to note that both studies were conducted exclusively in women and involved either chronic administration of testosterone to post-menopausal women (Zethraeus et al. 2009) or a single dose of testosterone to young women which produced supraphysiological concentrations of testosterone (Boksem et al. 2014). The precise dose of testosterone administered may be an important factor to consider in future research as some behavioral evidence suggests that testosterone may have a non-linear relationship with risk preferences (Stanton et al. 2011b). Also, neuroimaging studies suggest that testosterone can modulate brain function in men and women through both rapid (Goetz et al. 2014; van Wingen et al. 2009) and delayed (Hermans et al. 2008) mechanisms. Thus, it will be important for future research to consider the extent to which testosterone has immediate and/or delayed effects on risk preferences. Finally, more work will be needed to examine whether testosterone administration would modulate risk preferences in men. It is worth noting that testosterone administration has been found to similarly increase threat-related amygdala function in both men (Goetz et al. 2014) and women (Hermans et al. 2008) though each of these studies focused on a single sex and employed different designs and dosing levels. It is possible that men and women respond differently to the administration of testosterone in other domains such as economic risk taking. The organizational/activational hypothesis of testosterone-mediated behaviors suggest that androgen exposure at critical periods of development set the parameters for how the brain responds to later circulating levels of testosterone. Thus men may be more responsive to the administration of testosterone due to early organizational sex differences. Indeed, a number of animal studies have noted sex differences in the degree to which males and females respond behaviorally to testosterone administration in adulthood (see McHenry et al. 2014). A greater consideration of the organizing effects of prenatal and pubertal testosterone may help to enhance our understanding of how current levels of testosterone affect risk and decision-making in men and women. 


\section{Organizational Effects}

The ratio between the length of the second and the length of the fourth digit (2D:4D) is considered a marker of prenatal testosterone exposure (starting with Manning et al. 1998) ${ }^{7}$ and thus brain masculinization. This measure tends to be sexually dimorphic with men, on average, having lower ratios. The relationship between 2D:4D and testosterone exposure in utero is supposedly negative, such that a low 2D:4D is an indication of high testosterone exposure. In support of this, Lutchmaya et al. (2004) find that 2D:4D is negatively related to the fetal testosterone to estradiol ratio measured from amniotic fluid in a small mixed-sex sample of 29 children. Ventura et al. (2013) find similar results in a larger sample involving 106 newborns. There is also some evidence that individuals with congenital adrenal hyperplasia (CAH), a condition characterized by increased exposure to androgens in utero, have lower 2D:4D than control individuals (Brown et al. 2002; Ökten et al. 2002; Rivas et al. 2014; but see Buck et al. 2003 for a null result). Similarly, there is evidence suggesting that males with Klinefelter's syndrome, a condition associated with low fetal androgen levels, have higher 2D:4D than controls (Manning et al. 2013). One study also suggests that females with a male twin have more masculine digit ratios compared to females with a same sex twin, possibly due to androgen spillover from the male twin (van Anders et al. 2006 but see Hiraishi et al. 2012, for null replication). Interestingly, work on mice has shown testosterone administration in utero causes lower 2D:4D, whereas estrogen administration causes higher 2D:4D (Zheng and Cohn 2011). The same researchers also find that an inactivated androgen receptor leads to a higher 2D:4D, whereas an inactivated estrogen receptor leads to a lower 2D:4D. This latter study is perhaps the most convincing study on androgens and 2D:4D, but replications are needed.

Due to its ease of measurement, the relationship between 2D:4D and numerous traits and phenotypes has been examined; from myocardial infarction (Kyriakidis et al. 2010) and semen quality (Seo et al. 2010) to sexual orientation (see Grimbos et al. 2010 for review) and musical talent (Sluming and Manning 2000), with a mix of positive results, null results, and sometimes conflicting results or results only showing up for one sex. Lower 2D:4D has been associated with constructs loosely related to risk taking such as increased competitiveness in sports (Hönekopp et al. 2006; Manning and Taylor 2001) and profits in high frequency traders (Coates et al. 2009). Lower digit ratios are also weakly $(r=-.06)$, though significantly correlated with aggression in men (Hönekopp and Watson 2011). A growing number of studies have explored potential correlations between 2D:4D and economic risk taking, though the findings are mixed (see Table 1 for overview).

The first study to examine 2D:4D and economic risk taking was conducted by Dreber and Hoffman (2007) who examine the relationship in two different populations. Using a risk task similar to that of Apicella et al. (2008) reported above, they find that

\footnotetext{
${ }^{7}$ Note that Manning et al. (1998) find a negative correlation between circulating testosterone and 2D:4D in adult men, and interpret this as evidence of 2D:4D being a marker or prenatal testosterone exposure while Hönekopp et al. (2007) show in a meta-analysis, that 2D:4D and adult sex hormones are not related and instead interpret this as evidence of 2D:4D being a marker of prenatal testosterone exposure. When it comes to sex differences in 2D:4D, Hönekopp and Watson (2010) find a moderate sex difference in the right hand with males having lower 2D:4D in a meta-analysis.
} 
Table 1 Table of studies reporting results of 2D:4D and economic risk. Here we report whether reported tests conducted are significant (SIG) at the $5 \%$ level. If not significant, it is labeled NS. Empty cells denote that the test was either not conducted or not reported. Note that some of these studies are part of other larger studies that include additional predictor and outcome measures

\begin{tabular}{|c|c|c|c|c|c|c|c|c|c|c|}
\hline \multirow[t]{2}{*}{ Study } & \multicolumn{3}{|l|}{ Men } & \multicolumn{3}{|c|}{ Women } & \multicolumn{3}{|c|}{ Both sexes } & \multirow{2}{*}{$\begin{array}{l}\text { Correct for } \\
\text { multiple } \\
\text { comparison }\end{array}$} \\
\hline & Left & Right & Mean & Left & Right & Mean & Left & Right & Mean & \\
\hline $\begin{array}{l}\text { Dreber and Hoffman } 2007 \text {, } \\
\text { study } 1\end{array}$ & - & - & - & - & - & - & NS & NS & - & No \\
\hline $\begin{array}{l}\text { Dreber and Hoffman } 2007 \text {, } \\
\text { study } 2\end{array}$ & - & - & - & - & - & - & SIG & NS & - & No \\
\hline Apicella et al. 2008 & NS & NS & NS & - & - & - & - & - & - & No \\
\hline Sapienza et al. 2009 & NS & NS & NS & NS & NS & NS & NS & NS & NS & No \\
\hline $\begin{array}{l}\text { Branas-Garza and Rustichini } \\
\text { 2011, measure } 1\end{array}$ & - & SIG* & - & - & NS & - & - & NS & - & No \\
\hline $\begin{array}{l}\text { Branas-Garza and Rustichini } \\
\text { 2011, measure } 2\end{array}$ & - & SIG & - & - & NS & - & - & NS & - & No \\
\hline Garbarino et al. $2011^{* *}$ & - & - & - & - & - & - & - & - & SIG & No \\
\hline Drichoutis \& Nayga $2014 * * *$ & - & - & - & - & - & - & - & NS & - & Yes \\
\hline Schipper 2012, gain domain & - & NS & - & - & NS & - & - & - & - & Yes \\
\hline Schipper 2012, gain domain & - & NS & - & - & NS & - & - & - & - & Yes \\
\hline Dalton and Ghosal 2014 & - & NS & - & - & NS & - & - & NS & - & No \\
\hline Sytsma 2014, gain domain & NS & NS & NS & SIG & SIG & SIG & SIG & NS & NS & No \\
\hline Sytsma 2014, loss domain & SIG & NS & SIG & NS & NS & $\mathrm{NS}$ & $\mathrm{NS}$ & NS & NS & No \\
\hline $\begin{array}{l}\text { Sytsma 2014, average } \\
\text { of gain \& losses }\end{array}$ & SIG & NS & SIG & NS & NS & NS & SIG & NS & SIG & No \\
\hline
\end{tabular}

\begin{abstract}
* Significance here is in the opposite direction
**Note that they do not test sexes separately but rather find no significant interaction between 2D:4D and sex. It is unclear whether the effect between 2D:4D holds for both men and women but we assume it does. In addition, the authors note that the results do not qualitatively change when the median $2 \mathrm{D}: 4 \mathrm{D}$ of each hand is analyzed. Studies typically use the averages of finger measures conducted in triplicate
\end{abstract}

***Note that there were a number of tests conducted, but not separately for men and women

lower 2D:4D is associated with increased economic risk taking in a Swedish mixed-sex sample of 147 participants. While they report the results for both hands, the relationship is only statistically significant for the left hand. In their second sample of 116 Americans, they find no evidence of a relationship between 2D:4D and risk in either hand. Similarly, Apicella et al. (2008) find no relationship between economic risk taking and 2D:4D in the right hand, left hand or their average in an ethnically diverse sample of 98 American men - a result that remained insignificant even when ethnicity and other controls were included. ${ }^{8}$ Sapienza et al. (2009) find no association between financial risk taking and 2D:4D in a sample of male and female MBA students. The authors do however note a small but statistically insignificant relationship between

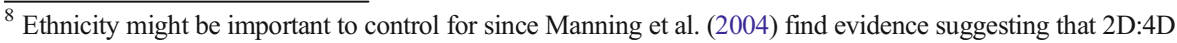
differs across ethnic groups.
} 
2D:4D and risk taking in women. 2D:4D in this study is measured as the average ratio of the subject's right and left hand but the results do not change when the hands are examined separately. Using a mixed-sex sample of 188 Caucasians, Branas-Garza and Rustichini (2011) examine the relationship between 2D:4D in the right hand with two different measures of economic risk involving hypothetical lotteries. In this study, 2D:4D in men is negatively related with only one of the two measures of economic risk taking, while 2D:4D in women instead is positively related to the other measure of risk taking. Garbarino et al. (2011) study a mixed-sex sample of 152 Caucasian participants and report a negative relationship between average 2D:4D of both hands and incentivized risk taking in lotteries in both men and women and the joint sample. They also find evidence of a non-linear effect of 2D:4D on economic risk taking. In a replication of this study, Sytsma (2014) also finds evidence of a negative relationship between left 2D:4D and economic risk taking in the gain domain, using a mixed-sex sample of 164 participants in Bangladesh. There is however no relationship for the right hand. Furthermore, when analyzing men and women separately, Sytsma finds that both the right and left digit ratio negatively correlate with risk taking, but only for women. When looking at risk taking in the domain of losses however, the author finds evidence of a negative relationship between risk taking and 2D:4D for men but not for women. However, this result is only significant for the average of the two hands and, when analyzed separately, the left hand. Besides for Apicella et al. (2008) and Sapienza et al. (2009), three other studies have reported null results across the board. In all three studies, only 2D:4D of the right hand is studied. Drichoutis and Nayga (2014) find no relationship between 2D:4D and lottery choices in a mixed-sex sample of 138 participants from Greece. Schipper (2012), in the same study as reported above, finds no relationship between 2D:4D and risk taking in men or women. Finally, Dalton and Ghosal (2014) find no relationship between 2D:4D and risk taking in hypothetical gambles in a mixed-sex sample of participants $(n=249)$ from the United Kingdom.

Results are thus equivocal for the relationship between 2D:4D and economic risk taking. Many studies have not found a relationship between 2D:4D and risk and of those studies that do report a significant result, most include at least one null result. Also, there are many ways to examine the association between risk and 2D:4D and not all studies report the same associations. Correlations are sometimes estimated in mixedsex samples and/or analyzed separately by sex. 2D:4D can also be examined independently for each hand or operationalized as the average of the two hands. ${ }^{9}$ Assuming only one measure of risk is employed, this means that nine possible associations can potentially be examined, which greatly increases the likelihood of type one errors. Also, corrections for multiple hypothesis testing are rare in this literature (see Table 1). This coupled with a potential file drawer problem that is common in science when null results are found may contribute to an over estimation of the number of significant findings. ${ }^{10}$

\footnotetext{
${ }^{9}$ One reason for the focus on the right hand may come from the fact that a meta-analysis finds that a sex difference in 2D:4D is larger for the right hand than for the left hand (Hönekopp and Watson 2010). However, the results from a meta-analysis suggest that among humans there is no effect of testosterone on the lateralization of the brain or behaviors, including handedness (Pfannkuche et al. 2009).

${ }^{10}$ For example, Anna Dreber and Moshe Hoffman have unpublished data indicating more null results on risk taking and 2D:4D in a South Asian Indian sample.
} 
As shown in Table 1, most studies do report 2D:4D results for the right hand and so we should consider this the most useful column to look at for reliable results since it is immune to reporting biases. Of the ten studies that report 2D:4D for the right hand in men only one is significant at the $5 \%$ level, in the correct direction. For women, the results are similar with only one out of nine studies finding a significant effect. When the sexes are combined, none of the ten studies find an effect. Thus, in total we find that on average we only get a significant result about $10 \%$ of the time for right 2D:4D. However, when one looks at the columns for the left hands or the mean of the hands it is interesting to note that there is a greater percentage of significant findings, even though there are less studies reporting the results. So for instance, of the studies that report 2D:4D for the left hand in men $40 \%$ of them find a significant effect. In fact, if we look at all the 28 cells that provide results for either the left hand or the mean of the hands in men, women or both sexes combined, 11 of them (40\%) are significant. This suggests that there may be some reporting bias. Again, it is exactly the columns with the least reported values that have a greater proportion of significant results.

There are other potential sources that may account for the inconsistencies found in the 2D:4D literature. For example, 2D:4D is an inherently noisy measure. Measurements are meant to reflect the length of the short bones of the fingers yet without radiographs this measurement relies upon the use of the proximal folds of the fingers, which may not overlap precisely with the ends of bones. Also, fat, water, blood and skin contribute further to the imprecision in this measurement. Taken together, we suggest that future work on 2D:4D use larger samples, adhere to uniform reporting of associations and correct for multiple comparisons when necessary.

While the brain is thought to be particularly sensitive to androgen exposure in utero, there is increasing evidence from animal studies that adolescence represents a second period of sensitivity for the organizing effects of androgens on the brain (for review Schulz et al. 2009). While hormonal concentrations can be measured directly during puberty, no studies have examined pubertal testosterone levels in relation to current and/or future economic risk taking. One putative marker of pubertal testosterone exposure is facial masculinity. Prior to puberty girls and boys faces are largely similar in shape. During puberty, however, it is largely the boys' features that begin to diverge. Since this happens during a period of increased gonadal testosterone production in boys, it is presumed that testosterone is responsible for this change, as is the case with the development of other secondary sexual characteristics. It has also been shown that boys with delayed puberty have more feminine facial shapes but when given testosterone exogenously their faces become more masculine as compared to controls not receiving testosterone (Verdonck et al. 1999).

While facial masculinity has been associated with a number of phenotypes including aggression (Goetz et al. 2013; Carré and McCormick 2008b) we know of only one study examining its relationship to economic risk taking. Apicella et al. (2008) find a positive and significant correlation between facial masculinity and risk. Specifically, they find that a one standard deviation increase in facial masculinity is associated with a $6 \%$ increase in the amount of money invested in a risky gamble. Other evidence that facial masculinity may be correlated with risky decision making comes from a study on expert chess players where risk taking is assessed from players' moves (Dreber et al. 2013). While no money is involved in this study, the measure of risk follows the standard definition of economic risk taking. The results suggest that facial masculinity 
and risk taking is negatively correlated in women though the relationship is not significant in men. To date, very little work has examined the relationship between pubertal testosterone and economic risk taking. As a result, these findings should be met with some caution and replications are encouraged. Moreover, neither study provides causal evidence that testosterone in puberty leads to increased risk taking in adulthood. It is possible that a masculine appearance itself leads to increased risk taking or that facial masculinity is associated with other traits that directly influence risk taking (Apicella et al. 2008).

\section{Testosterone and Risk Related Constructs}

The literature on androgens and non-financial risk taking is large, especially when one also considers the work conducted on non-human animals. Here we will discuss a few additional studies in humans that help to inform our understanding of testosterone's role in economic decision-making involving risk. While many of these studies are also correlational there are at least two studies that have causally linked testosterone administration to general measures of risk taking. van Honk et al. (2004) examine the effects of testosterone administration on risk taking in small sample of women $(n=$ 12) using the Iowa Gambling Task (IGT; Bechara et al. 1994). In this task, probabilities of winning and losing are ambiguous but can be learned during the task itself. The researchers find that testosterone administration leads to disadvantageous decisionmaking. Individuals receiving testosterone are more likely to choose options associated with larger rewards but more frequent and severe punishment. Similarly, Stanton et al. (2011a) find that circulating testosterone correlates positively with risk taking in the IGT in a larger mixed-sex sample ( $n=154,78$ men, 76 women). The second study attempting to causally link high testosterone to risk taking was conducted on a similarly small sample of men (Goudriaan et al. 2010). In this study, 19 men were either given an aromatase inhibitor $(n=10)$, leading to high-normal testosterone levels and low-normal levels of estradiol, or an aromatase inhibitor combined with estradiol $(n=9)$, leading to low-normal testosterone levels and high-normal levels of estradiol. The researchers then compared the groups' decision-making in three different risk tasks. Men in the high-normal testosterone group were more risk seeking in a balloon analogue risk task (BART: Lejuez et al. 2002) where probabilities are unknown but not in the IGT task or a dice task. It is possible that the inconsistent results within and between these two studies may reflect differences in the tasks and/or samples. As mentioned, it is possible that testosterone modulates risk taking behavior in a sex-dependent manner due to sex differences in the early organizing effects of testosterone on the brain. More work will be needed to examine the extent to which testosterone has similar effects on different measures of risk related preferences and in men and women.

There are a number of studies that examine the link between testosterone and behavioral constructs related to financial risk taking. For example, Apicella et al. (2011) study men's willingness to compete. This measure, where participants choose to solve a task and get paid according to a piece-rate scheme or a tournament scheme is typically positively correlated with economic risk taking (e.g., Niederle and Vesterlund 2007). However, Apicella et al. failed to find a correlation between circulating testosterone, facial masculinity and 2D:4D and competitiveness. Similar null results were obtained by Schipper (2014) who examined the relationship between testosterone and 
competitive bidding behavior in symmetric independent private value first-price auctions. Bidding and profits are considered to be proxies of risk aversion (as discussed in Schipper 2014). Ronay and von Hippel (2010a) explore the interaction between power manipulations, where participants are asked to recall situations in which they had high or low power, and 2D:4D to predict risk taking in the BART and a modified BART which could result in mild electric shocks. In a first study $(n=59)$, they find that men with low right hand 2D:4D are more risk taking when they are primed with low power. In a second study $(n=65)$, they replicate this effect and also find that men with low right hand 2D:4D are less risk taking when primed with high power. Stenstrom et al. (2011), using survey measures of risk taking in different domains, find that right hand 2D:4D is negatively related to self-reported financial risk taking (related to risky financial investments) in an ethnically heterogenous sample of men $(n=219)$, but not in a subsample of male Caucasians $(n=130)$. No relationships are found for women $(n=194)$. Pearson and Schipper (2012), in a mixed-sex sample of 400 participants, find no correlation between right hand 2D:4D and bidding or profits in symmetric independent private value first-price auctions.

There have been attempts to relate testosterone to risk related decisions outside the lab. White et al. (2006), in a sample of 110 male MBA students, find that those with substantial experience in new venture creation, a risky business endeavor, have significantly higher baseline testosterone levels than others. Coates and Herbert (2008) study testosterone and cortisol levels among 17 male traders in the financial industry and find that testosterone levels in the morning predict profitability during the day. Here profitability is assumed to be a function of risk taking. Sapienza et al. (2009) find that high circulating testosterone and low 2D:4D can predict which MBA students choose a risky finance career. Coates et al. (2009) find that right 2D:4D correlates negatively with long term profitability and time spent working as a trader in a sample of 44 male traders, In a separate paper, Coates and Page (2009) report that this relationship is mainly due to low 2D:4D traders being more risk tolerant as inferred from trading data. Ronay and von Hippel (2010b) study physical risk taking among young male skateboarders and find that it increases when an attractive female observer is present compared to a male observer. This increase is thought to be mediated by an increase in testosterone. While men exposed to the attractive confederate had higher levels of testosterone, the authors did not collect a baseline value and so it is not possible to confirm this mechanism. Cronqvist et al. (2014) compare investment portfolio decisions in women with a male versus female dizygotic twin. Women with a male versus female co-twin, own a greater share of risky and volatile stocks.

\section{Neural and Psychological Pathways of Economic Risk-Taking}

In so far that testosterone influences economic risk-taking, understanding the neural and psychological channels by which this occurs is paramount for developing comprehensive models of choice under risk. During the last decade, neuroeconomic studies have revealed a complex neural circuitry involved in reward processing, including reward value encoding, prediction, and risk. Key players in this circuitry include the orbitofrontal cortex (OFC), the anterior cingulate cortex (ACC), the amygdala $(\mathrm{AMYG})$ and the ventral striatum (VS) and more specifically the nucleus accumbens (NAc). It is possible that testosterone influences decision-making through actions in 
one or more of these structures. Here we pay particular attention to the $\mathrm{OFC}$, and the mesolimbic dopaminergic pathway in the brain, which includes the VS and NAc.

One possible starting point for decision-making is the OFC, which is thought to play a critical role in the encoding of reward (see Kennerley and Walton 2011 for review). A number of studies find that cells within the OFC fire in anticipation of expected outcomes (for instance, Gottfried et al. 2003; Tremblay and Schultz 1999; PadoaSchioppa and Assad 2006). Other studies reveal that activation of the OFC reflects both preference order and reward magnitude (see Kennerley and Walton 2011 for review). Furthermore, the OFC has been implicated in decisions involving risk. For example, damage to the ventromedial prefrontal cortex, which includes parts of the OFC, has been associated with risky and disadvantageous decision-making (Bechara et al. 1997, but see Maia and McClelland 2004 for critique). Moreover, the OFC as well as the ACC have been shown to respond to increased variance in risk (Rogers et al. 1999). Other elements and constructs related to risk-taking such as impulsivity (Rudebeck et al. 2006) and aggression (Mehta and Beer 2010) have also implicated the OFC. In a recent study, activation in the lateral OFC and $A M Y G$ following exposure to emotional-cues was related to negative urgency and that negative urgency mediated the relationship between this activation and measures of general risk-taking (Cyders et al. 2014). It is important to note that not all studies have implicated the OFC in risky decision-making. For example, Kuhnen and Knutson (2005) find that that while activation in the OFC and ACC is observed during gain outcomes, the level of activation does not predict subsequent risky behavior. Nevertheless, it is possible that testosterone influences economic risk taking through its effects on the OFC and/or connected regions. Stanton et al. (2011a, b) suggest that testosterone induced suppression of the OFC may increase desire for monetary rewards and decrease sensitivity to punishment. However, there is currently no research to suggest that testosterone modulates OFC reactivity to reward-related processes using fMRI. Still some work indicates a positive correlation between testosterone concentrations and threat-related OFC function (Manuck et al. 2010). However, experimental work yields contradictory results with one study demonstrating heightened OFC reactivity to threat-related facial expressions after testosterone administration (Hermans et al. 2008) and two studies reporting decreased OFC reactivity to threat-related facial expressions after testosterone administration (van Wingen et al. 2009; Goetz et al. 2014). In addition, another study reported that decreased OFC reactivity to social provocation mediated the relationship between endogenous testosterone concentrations and aggressive behavior (Mehta and Beer 2010). Thus the relationship between OFC reactivity and testosterone are not clear. It also has been suggested that testosterone may affect behavior by attenuating OFC-AMYG connectivity. Specifically, the AMYG, a brain structure involved in emotion processing may be less influenced by top-down prefrontal control when testosterone is high. Exogenous testosterone administration reduces OFC-AMYG coupling (van Wingen et al. 2010). Moreover, Bos et al. (2012a) find that testosterone administration reduces the functional connectivity between the AMYG and OFC in subjects during ratings of trustworthiness from faces. The researchers speculate that testosterone, possibly by augmenting dopamine synthesis or release, leads to more vigilant responses of the AMYG to untrustworthiness. Whether the influence of testosterone on connectivity between prefrontal regions and the AMYG is important to economic risk-taking remains to be seen. It is also valuable to note that the AMYG 
itself is rich in androgen and estrogen receptors and so the behavioral effects of testosterone may, in part, be mediated via its interaction with androgen receptors or its downstream metabolites interacting with estrogen receptors.

Finally, relevant to studies linking prenatal testosterone to economic risk-taking, fetal testosterone levels have also been associated with gray matter volume in parts of the OFC (Lombardo et al. 2012). Not surprisingly gray matter volume in the OFC is also greater in women (Lombardo et al. 2012). Thus, if prenatal testosterone leads to increased risk-taking in adulthood this may be one potential channel by which this occurs.

Testosterone's euphorigenic and potentially addictive properties are widely known (see Frye 2007). Testosterone and its metabolites dihydrotestosterone (DHT) and $3 \alpha-$ androstanediol ( $3 \alpha$-diol) may achieve these effects through their interactions with the mesolimbic dopaminergic reward pathway in the brain, including the VS and more specifically the NAc, which are known to play important roles in both reward processing and reward seeking behavior. When testosterone is injected into the NAc of rodents induces conditioned place preference (Packard et al. 1997) and this effect can be blocked by the $\alpha$-flupenthixol, a DA antagonist (Packard et al. 1998). While these data suggest that these brain regions play a role in testosterone's rewarding and reinforcing properties, it remains unclear whether this is mediated by dopamine release or some other mechanism. In one study on male hamsters testosterone administration did not increase dopamine levels in the NAc (Triemstra et al. 2008). Nevertheless, the reinforcing properties of testosterone suggest that this may be one means by which organisms adaptively modulate their behavior. Any behavior that produces a surge in testosterone is likely to be reinforced.

Imaging studies demonstrate VS activation to both the anticipation and delivery of rewards, including monetary rewards (O'Doherty 2004). Moreover, other work indicates that heightened VS reactivity in anticipation of monetary reward predicts risky financial decision making and risk-seeking mistakes (Kuhnen and Knutson 2005). Finally, preferences for immediate versus delayed rewards are positively correlated with the magnitude of VS reactivity to reward (Hariri et al. 2006). Notably, a separate body of evidence has linked individual differences in testosterone concentrations to reward-related neural function. Specifically, testosterone concentrations among adolescent boys and girls are positively correlated with VS reactivity to the anticipation of reward (Forbes et al. 2010) and to the delivery of reward (Op de Macks et al. 2011, but see Forbes et al. 2010). More compelling evidence for the role of testosterone in modulating VS function comes from pharmacologic-fMRI work. Specifically, Hermans et al. (2010) found that a single administration of testosterone to healthy young women led to increased VS reactivity to cues signaling potential reward versus nonreward. To the extent that testosterone plays a causal role in modulating risk preferences, and risk-taking behavior more generally (e.g., van Honk et al. 2004), the above data suggest that testosterone may do so through modulation of VS function. Future research involving direct manipulation of testosterone and measurement of riskpreferences or risk-taking behavior during fMRI will be needed to test this proposed mechanism.

While testosterone may influence financial risk-taking directly via its effects on the brain, it is also possible that its effects are indirect. For instance, it has been suggested that baseline testosterone may serve as a marker of individual differences (Sellers et al. 
2007) and these differences may instead influence the propensity for risk. Indeed, previous work has linked testosterone with implicit need for power (Schultheiss et al. 1999), dominance (Cashdan 1995), rule violation and crime (Dabbs et al. 1995), sensation seeking (Aluja and Torrubia 2004; Campbell et al. 2010), mood, and threat vigilance (van Honk et al. 1999). Likewise, other studies have identified links between various forms of risk-taking behavior and personality traits, such as sensation seeking, aggression, sociability (e.g. Zuckerman and Kuhlman 2000) and power motivation (McClelland and Watson 1973). In a more recent study involving over 2000 men and women, risk taking in six decision domains (e.g. recreation, health, career, finance, safety and social) was examined in relation to the Big Five personality traits (Nicholson et al. 2005). Overall risk taking in this study was associated with high extraversion and openness and low agreeableness neuroticism, and conscientiousness. One implication of findings such as this is that risk taking may be best conceived as a relatively stable dispositional trait. This assumption however, has not gone unchallenged. A number of studies have highlighted the importance of context and framing on decision involving risk (e.g. Tversky and Kahneman 1986; Ronay and von Hippel 2010b) while other research suggests that there is little within-participant consistency in financial risk taking across different payoff domains and response modes (Shoemaker 1990). More recent studies that employ different risk scales find large within-participant variation in risk measures across different decision domains, including health, social and economic risks (Blais and Weber 2006; Hanoch et al. 2006). Thus the role of personality on economic risk preferences is, at present, elusive.

Another stable characteristic that may be related to risk taking is a person's chronotype. In a relatively small mixed sex sample, Killgore (2007) found that evening types scored higher than morning types in self-reported risk-propensity but not in a behavioral measure (e.g. BART). In a larger sample, Maestripieri (2014) found that evening types scored higher on risk-taking. However, this effect was specific to women. Intriguingly, one study reported that people with evening types had elevated testosterone concentrations relative to morning types (Randler et al. 2012), suggesting that sleep cycles may play a role in the previously observed relationship between endogenous testosterone and risk. Other work with a much larger sample size failed to detect an association between chronotype and testosterone in either men or women (Maestripieri 2014). Nevertheless, future work should examine whether links between personality and other stable behavioral traits and economic risk-taking are mediated by variation in testosterone concentrations. Moreover, given the reciprocal relationship between hormones and behavior it is also possible that personality traits influence neuroendocrine function, which in turn, predisposes one to adopt risk-seeking behavioral strategies. Discerning the importance of these associations and their possible causal pathways are important directions for future research.

\section{Discussion}

In the last 50 years behavioral endocrinology has emerged as a powerful tool for understanding a wide variety of behaviors in humans and non-human animals. However, the study of hormones on economic decision-making is in its early stages and much remains unanswered. There are good reasons to suspect that testosterone 
mediates economic risk taking. Such a finding would be consistent with a number of observations including lower levels of risk taking in women and older-aged individuals and increases in risk taking in men following monetary wins (e.g. the house money effect) and when in the presence of attractive women (Apicella et al. 2014). While a number of association studies have identified a positive link between circulating testosterone and risk taking, not all of the associations have been linear (see Stanton et al. 2011b). Few studies have experimentally manipulated testosterone. In a quasiexperimental design, Apicella et al. (2014) find that increases in testosterone in men were associated with increases in economic risk taking. However, of the only two studies that have exogenously administered testosterone, both failed to find an effect in women. Also, at present, evidence for the influence of prenatal and pubertal testosterone is weak. Still, the field is in its infancy - it has not yet been 10 years since the first papers emerged suggesting a link between hormones and economic risk taking (Apicella et al. 2008; Coates and Herbert 2008). Given the complexity of the hormones and the behaviors we are studying, the precise nature of this link may not be realized without considerable efforts. That said, hormonal measurement is noninvasive and relatively inexpensive especially compared to neuroimaging techniques, which have become mainstream in the field of economics. Accordingly, we believe the study of hormones on economic decision-making holds great promise and should be pursued as intently as the neural substrates. Here we outline five concrete recommendations that we believe will help engender a better understanding of behavioral-hormonal relationships in the field of economics.

1. We suggest that future work examine the reciprocal relationships between economic behavior, outcomes and testosterone. Many studies now indicate that hormones and behavior are mutually reinforcing. Steroid hormones influence the propensity to engage in certain behaviors but those behaviors and their outcomes can also affect hormone levels. For instance: Does the mere act of engaging in financial risk taking, regardless of outcome, affect testosterone levels? If so, is the amount of money risked or how it was earned important in influencing the degree of testosterone change? Relatedly, how does winning or losing money affect testosterone levels? Do individuals react to wins and losses in ways consistent with loss aversion? That is, do individuals experience proportionally greater declines in testosterone as a result of losing money than increases in testosterone as a result of losing money? Finally, does it matter if the money won or lost belonged to the subject or someone else, such as their family member, co-worker or financial advisee? These are all interesting and important questions for future research. Such research may also provide insights into mechanisms involved with gambling addictions.

2. We know from human and animal research that life stages and social contexts are strong endocrine determinants (Becker 2002). Animals evolved to adjust their behavior adaptively to different circumstances by integrating environmental cues with internal states (Becker 2002; O’Connell and Hofmann 2011). Paradoxically, this means that the same hormone can trigger different behaviors depending on the context. For instance, testosterone release in males is associated with both mating and fighting. An important illustrative demonstration of the role of environment and hormone interactions was shown with California mice (Gleason et al. 2009). 
Mice who won mock fighting competitions and received testosterone were more likely to win future competitions compared to mice who did not win but received testosterone and compared to mice who won but did not receive testosterone. This research underscores the importance of context on hormone-behavior relationships. As such, we suggest that careful attention be paid to past economic experience as well as the larger contexts in which studies are taking place.

Additionally, it remains to be seen whether situations far removed from financial contexts, but with discernible effects on testosterone, could also affect financial risk. One stylized fact is that stock markets of countries whose teams lose major sporting events suffer negative returns the day following the loss (Edmans et al. 2007). Since testosterone has been found to decrease in fans of losing sports teams (Bernhardt et al. 1998), this may be one mechanism by which this occurs (Apicella et al. 2014). Most decision theories such as expected utility theory, prospect theory or even reinforcement learning theories all, in the end, share a common conclusion. That is, decision-makers integrate various dimensions of an option into a single measure of its subjective value and then choose the option that is worth the most. If unconnected and independent events have spillover effects in financial decision domains, via testosterone change, then these theories may need to be adjusted to account for this. It is possible that testosterone affects the valuation or experience of different options though this remains an empirical question.

3. While correlational studies provide important and often first insights into hormonebehavior relationships, the field needs administration studies involving testosterone to examine potential cause and effect relationships. We suggest that future studies first focus on men since female endocrinology is more complicated - not only do monthly shifts in hormones occur in reproductive-aged women but also, hormonal profiles shift dramatically with life events, including pregnancy, lactation and menopause. Many administration studies also use Androgel to increase testosterone, which is slow acting and does not mimic the natural surges in testosterone that occur in behavioral studies. Future work should employ pharmacological protocols that mimic acute changes in testosterone. Because manipulating hormones is not always possible, we also advocate for the study of individuals, both men and women, with endocrine abnormalities as they may also offer some understanding of both activational and organizational behavioral effects of testosterone.

4. The study of economic decision-making would benefit from integrating both methods and insights from neuroscience, endocrinology, and genetics. As of yet, we know of no work that has collectively examined financial risk taking at the hormonal, neuronal, genetic level. While such undertaking may be difficult and expensive, the joint explanatory potential may be substantial. In our opinion, no one genetic, hormonal or brain mechanism has yet been identified that offers sufficient explanatory power to be useful in predicting heterogeneity in financial risk taking. Interdisciplinary approaches may also reveal important interactions between genes and environments and their biological pathways. Such findings may help shed light on inconsistent findings in testosterone research. For instance, associations between testosterone and risk taking behavior may depend on genetic differences in the androgen receptor (AR) gene. Notably, in vitro work indicates that the transactivation potential of the AR declines linearly with an increase in the number of CAG tri-nucleotide repeats (Chamberlain et al. 1994). Consistent with 
this idea, recent evidence indicates that testosterone is positively correlated with a self-report measure of risk taking in adolescent boys, but only in those with fewer AR CAG repeats (Vermeersch et al. 2010).

5. While most endocrinologists agree that testosterone shapes the brain during critical periods of development, there is currently little evidence to suggest that these critical periods affect economic decision-making and risk later in life. At the very best, 2D:4D offers us an indirect and noisy measure of androgen exposure in utero. As such, if we are going to resolve whether it affects risk taking in later life, we need to conduct studies with larger samples and adhere to uniform reporting practices so false positives, false negatives and file drawer effects can be avoided. Currently, many studies report 2D:4D for the right hand only. This is conducted under the assumption that androgens in utero lead to the lateralization of the brain and behavior. This assumption itself is controversial (for meta-analysis see Pfannkuche et al. 2009). Since 2D:4D is extremely cheap and quick measure to take there is little reason to exclude left hand measurements. If anything, including null effects for the left hand may help elucidate the specific biological pathways via which prenatal androgens act.

Like 2D:4D, facial masculinity is a supposed marker of pubertal androgen exposure, and accordingly this may have some relevance for economic risk taking in adulthood. Thus far only one study has examined this (Apicella et al. 2008) and so the findings, until they are replicated, should be met with some degree of skepticism. Also, unlike androgens in utero, pubertal testosterone levels can be safely measured. We think that longitudinal correlational studies that examine testosterone levels and economic risk taking pre and post puberty would provide an important contribution to this understudied area of research.

\section{Conclusion}

Pleiotropic outcomes are common with hormones and testosterone is no exception. A myriad number of behavioral phenotypic effects of testosterone have been unearthed in the last few decades. For this reason, economists can no longer afford to be agnostic about their potential effects on decision-making. We believe that a research paradigm incorporating neural, genetic as well as hormonal substrates will ultimately lead to a richer understanding of the complex reciprocal relationships that exists between biology, behavior and environment.

Acknowledgments The authors would like to thank their three reviewers and Dario Maistripieri for their suggestions and thoughtful feedback, and the Jan Wallander and Tom Hedelius Foundation (Svenska Handelsbankens Forskningsstiftelser) and the Knut and Alice Wallenberg Foundation for financial support.

\section{References}

Adkins-Regan, E. (2005). Hormones and animal social behavior. Princeton: Princeton University Press.

Aluja, A., \& Torrubia, R. (2004). Hostility-aggressiveness, sensation seeking, and sex hormones in men: reexploring their relationship. Neuropsychobiology, 50, 102-107. 
Apicella, C. L., \& Cesarini, D. A. (2011). Testosterone and the biology of politics: experimental evidence from the 2008 presidential election. In P. K. Hatemi \& R. McDermott (Eds.), Man is by nature a political animal: evolution, biology, and politics (pp. 261-272). Chicago: University of Chicago Press.

Apicella, C. L., Dreber, A., Campbell, B., Gray, P., Hoffman, M., \& Little, A. C. (2008). Testosterone and financial risk preferences. Evolution and Human Behavior, 29, 384-390.

Apicella, C. L., Dreber, A., Gray, P. B., Hoffman, M., Little, A. C., \& Campbell, B. C. (2011). Androgens and competitiveness in men. Journal of Neuroscience Psychology and Economics, 4, 54-62.

Apicella, C. L., Dreber, A., \& Mollerstrom, J. (2014). Salivary testosterone change following monetary wins and losses predicts future financial risk taking. Psychoneuroendocrinology, 39, 58-64.

Archer, J. (2006). Testosterone and human aggression: an evaluation of the challenge hypothesis. Neuroscience \& Biobehavioral Reviews, 30, 319-345.

Balthazart, J. (1983). Hormonal correlates of behavior. In D. S. Farner, J. R. King, \& K. C. Parkes (Eds.), Avian biology (pp. 221-365). New York: Academic.

Barsky, R. B., Juster, F. T., Kimball, M. S., \& Shapiro, M. D. (1997). Preference parameters and behavioral heterogeneity: an experimental approach in the health and retirement study. Quarterly Journal of Economics, 112, 537-579.

Beatty, W. W. (1979). Gonadal hormones and sex differences in nonreproductive behaviors in rodents: organizational and activational influences. Hormones and Behavior, 12(2), 112-163.

Bechara, A., Damásio, A. R., Damásio, H., \& Anderson, S. W. (1994). Insensitivity to future consequences following damage to human prefrontal cortex. Cognition, 50(1-3), 7-15.

Bechara, A., Damasio, H., Tranel, D., \& Damasio, A. R. (1997). Deciding advantageously before knowing the advantageous strategy. Science, 275(5304), 1293-1295.

Becker, J.B. (Ed.). (2002). Behavioral endocrinology. MIT Press.

Benjamin, D. J., Cesarini, D., van der Loos, M. J. H. M., Dawes, C. T., Koellinger, P. D., et al. (2012). The genetic architecture of economic and political preferences. Proceedings of the National Academy of Sciences of the United States of America, 109, 8026-8031.

Bernhardt, P. C., Dabbs, J. M., Jr., Fielden, J. A., \& Lutter, C. D. (1998). Testosterone changes during vicarious experiences of winning and losing among fans at sporting events. Physiology \& Behavior, 65(1), 59-62.

Blais, A. R., \& Weber, E. U. (2006). A domain-specific risk-taking (DOSPERT) scale for adult populations. Judgment and Decision Making, 1(1), 33-47.

Boksem, M. A., Mehta, P. H., Van den Bergh, B., van Son, V., Trautmann, S. T., Roelofs, K., Smidts, A., \& Sanfey, A. G. (2014). Testosteroneinhibits trust but promotes reciprocity. Psychological Science, 24, 2306-2314.

Booth, A. L., \& Nolen, P. J. (2012). Gender differences in risk behaviour: does nurture matter? The Economic Journal, 122(558), F56-F78.

Bos, P. A., Hermans, E. J., Ramsey, N. F., \& Van Honk, J. (2012a). The neural mechanisms by which testosterone acts on interpersonal trust. NeuroImage, 61(3), 730-737.

Bos, P. A., Panksepp, J., Bluthé, R. M., \& Honk, J. V. (2012b). Acute effects of steroid hormones and neuropeptides on human social-emotional behavior: a review of single administration studies. Frontiers in Neuroendocrinology, 33(1), 17-35.

Branas-Garza, P., \& Rustichini. A. Organizing effects of testosterone and economic behavior: not just risk taking. PLoS ONE, 6, e29842.

Brown, W. M., Hines, M., Fane, B. A., \& Breedlove, S. M. (2002). Masculinized finger length patterns in human males and females with congenital adrenal hyperplasia. Hormones and Behavior, 42(4), 380-386.

Buck, J. J., Williams, R. M., Hughes, I. A., \& Acerini, C. L. (2003). In-utero androgen exposure and 2nd to 4th digit length ratio-comparisons between healthy controls and females with classical congenital adrenal hyperplasia. Human Reproduction, 18(5), 976-979.

Camerer, C. (2003). Behavioral game theory: experiments in strategic interaction. Princeton: Princeton University Press.

Campbell, B. C., Dreber, A., Apicella, C. L., Eisenberg, D. T. A., Gray, P. B., Little, A. C., Garcia, J. R., Zamore, R. S., \& Lum, J. K. (2010). Testosterone exposure, dopaminergic reward, and sensation-seeking in young men. Physiology and Behavior, 99(4), 451-456.

Carney, D. R., Cuddy, A. J. C., \& Yap, A. J. (2010). Power posing: Brief nonverbal displays affect neuroendocrine levels and risk tolerance. Psychological Science, 21(10), 1363-1368.

Carré, J. M., \& McCormick, C. M. (2008a). Aggressive behavior and change in salivary testosterone concentrations predict willingness to engage in a competitive task. Hormones and Behavior, 54, 403-409.

Carré, J. M., \& McCormick, C. M. (2008b). In your face: facial metrics predict aggressive behaviour in the laboratory and in varsity and professional hockey players. Proceedings of the Royal Society of London B: Biological Sciences, 275, 2651-2656. 
Carré, J. M., Putnam, S. K., \& McCormick, C. M. (2009). Testosterone responses to competition predict future aggressive behaviour at a cost to reward in men. Psychoneuroendocrinology, 343, 561-570.

Carré, J. M., McCormick, C. M., \& Hariri, A. R. (2011). The social neuroendocrinology of human aggression. Psychoneuroendocrinology, 36, 935-944.

Carré, J. M., Campbell, J. A., Lozoya, E., Goetz, S. M., \& Welker, K. M. (2013). Changes in testosterone mediate the effect of winning on subsequent aggressive behaviour. Psychoneuroendocrinology, 38, 2034 2041.

Carré, J. M., Iselin, A. M., Welker, K. M., Hariri, A. R., \& Dodge, K. A. (2014a). Lowered testosterone reactivity mediates the effect of early intervention on aggressive behavior. Psychological Science, 25, 230-236.

Carré, J. M., Baird-Rowe, C., \& Hariri, A. R. (2014b). Testosterone responses to competition predict decreased trust ratings of emotionally neutral faces. Psychoneuroendocrinology, 19, 79-83.

Cashdan, E. (1995). Hormones, sex, and status in women. Hormones and Behavior, 29(3), 354-366.

Cesarini, D., Johannesson, M., Lichtenstein, P., Sandewall, Ö., \& Wallace, B. (2010). Financial risk taking behavior is genetically transmitted. Journal of Finance, 65(5), 1725-1754.

Chamberlain, N. L., Driver, E. D., \& Miesfeld, R. L. (1994). The length and location of CAG trinucleotide repeats in the androgen receptor N-terminal domain affect transactivation function. Nucleic Acids Research, 22, 3181-3186.

Coates, J., \& Herbert, J. (2008). Endogenous steroids and financial risk taking on a London trading floor. Proceedings of the National Academy of Sciences, 105, 6167-6172.

Coates, J., \& Page, L. (2009). A note on trader Sharpe ratios. PLoS ONE, 4, e8036.

Coates, J., Gurnell, M., \& Rustichini, A. (2009). Second-to-fourth digit ratio predicts success among highfrequency financial traders. Proceedings of the National Academy of Sciences, 106, 623-628.

Cronqvist, H., Previtero, A., Siegel, S., \& White, R.T. (2014). The fetal origins hypothesis in finance: prenatal environment and financial risk taking. Mimeo.

Cyders, M. A., Dzemidzic, M., Eiler, W. J., Coskunpinar, A., Karyadi, K. A., \& Kareken, D. A. (2014). Negative urgency mediates the relationship between amygdala and orbitofrontal cortex activation to negative emotional stimuli and general risk-taking. Cerebral Cortex, bhu123.

Dabbs, J. M., Jr. (1990). Salivary testosterone measurements: reliability across hours, days, and weeks. Physiology and Behavior, 48, 83-86.

Dabbs, J. M., Jr., Carr, T. S., Frady, R. L., \& Riad, J. K. (1995). Testosterone, crime, and misbehavior among 692 male prison inmates. Personality and Individual Differences, 18(5), 627-633.

Dalton, P.S., \& Ghosal, S. (2014). Self-confidence, overconfidence and prenatal testosterone exposure: evidence from the lab. Mimeo.

Day, C. S., \& Galef, B. G. (1977). Pup cannibalism: one aspect of maternal behavior in golden hamsters. Journal of Comparative and Physiological Psychology, 91(5), 1179-1189.

Dekel, E., \& Scotchmer, S. (1999). On the evolution of attitudes towards risk in winner-take-all games. Journal of Economic Theory, 87, 125-143.

Dixson, A. F. (1998). Primate sexuality: comparative studies of the prosimians, monkeys, apes and human beings. New York: Oxford University Press.

Do Rego, J. L., Seong, J. Y., Burel, D., Leprince, J., Luu-The, V., Tsutsui, K., \& Vaudry, H. (2009). Neurosteroid biosynthesis: enzymatic pathways and neuroendocrine regulation by neurotransmitters and neuropeptides. Frontiers in Neuroendocrinology, 30(3), 259-301.

Dohmen, T., Falk, A., Huffman, D., Sunde, U., Schupp, J., \& Wagner, G. G. (2011). Individual risk attitudes: measurement, determinants and behavioral consequences. Journal of the European Economic Association, 9(3), 522-550.

Dreber, A, \& Hoffman, M. (2007). Portfolio selection in utero. Mimeo, Stockholm School of Economics.

Dreber, A., Apicella, C. L., Eisenberg, D. T., Garcia, J. R., Zamore, R. S., Lum, J. K., \& Campbell, B. (2009). The $7 \mathrm{R}$ polymorphism in the dopamine receptor DRD4 is associated with financial risk taking in men. Evolution and Human Behavior, 30(2), 85-92.

Dreber, A., Gerdes, C., Gränsmark, P., \& Little, A. C. (2013). Facial masculinity predicts risk and time preferences in expert chess players. Applied Economics Letters, 20(16), 1477-1480.

Drichoutis, A. C., \& Nayga, R. M., Jr. (2014). Do risk and time preferences have biological roots? Southern Economic Journal, forthcoming.

Edmans, A., Garcia, D., \& Norli, O. (2007). Sports sentiment and stock returns. Journal of Finance, 62, 1967-1998.

Ellison, P. T., Bribiescas, R. G., Bentley, G. R., Campbell, B. C., Lipson, S. F., Panter-Brick, C., \& Hill, K. (2002). Population variation in age-related decline in male salivary testosterone. Human Reproduction, 17(12), 3251-3253.

Forbes, E. E., Ryan, N. D., Phillops, M. L., Manuck, S. B., Worthman, C. M., Moyles, D. L., Tarr, J. A., Sciarrillo, S. R., \& Dahl, R. E. (2010). Healthy adolescents' neural response to reward: associations with 
puberty, positive affect, and depression symptoms. Journal of the Academy of Child and Adolescent Psychiatry, 49, 162-172.

Frye, C. A. (2007). Some rewarding effects of androgens may be mediated by actions of its 5a-reduced metabolite 3aandrostanediol. Pharmacology Biochemistry and Behavior, 86(2), 354-367.

Garbarino, E., Slonim, R., \& Sydnor, J. (2011). Digit ratios (2D:4D) as predictors of risky decision making for both sexes. Journal of Risk and Uncertainty, 42, 1-26.

Geniole, S. N., Busseri, M. A., \& McCormick, C. M. (2013). Testosterone dynamics and psychopathic personality traits independently predict antagonistic behavior towards the perceived loser of a competitive interaction. Hormones and Behavior, 64, 790-798.

Gleason, E. D., Fuxjager, M. J., Oyegbile, T. O., \& Marler, C. A. (2009). Testosterone release and social context: when it occurs and why. Frontiers in Neuroendocrinology, 30(4), 460-469.

Gneezy, U., \& Potters, J. (1997). An experiment on risk taking and evaluation periods. Quarterly Journal of Economics, 112(2), 631-645.

Goetz, S. M. M., Tang, L., Thomason, M. E., Diamond, M. P., Hariri, A. R., \& Carré, J. M. (2013). Testosterone rapidly increases neural reactivity to threat in healthy men: a novel two-step pharmacological challenge paradigm. Biological Psychiatry, 76, 324-331.

Goetz, S. M., Shattack, K. S., Miller, R. M., Campbell, J. A., Lozoya, E., Weisfeld, G. E., \& Carré, J. M. (2013). Social status moderates the relationship between facial structure and aggression. Psychological Science, 24, 2329-2334.

Gottfried, J. A., O’Doherty, J., \& Dolan, R. J. (2003). Encoding predictive reward value in human amygdala and orbitofrontal cortex. Science, 301(5636), 1104-1107.

Goudriaan, A. E., Lapauw, B., Ruige, J., Feyen, E., Kaufman, J.-M., Brand, M., \& Vingerhoets, G. (2010). The influence of high-normal testosterone levels on risk taking in healthy males in a 1-week letrozole administration study. Psychoneuroendocrinology, 35, 1416-1421.

Grimbos, T., Dawood, K., Burris, R. P., Zucker, K. J., \& Puts, D. A. (2010). Sexual orientation and the second to fourth finger length ratio: a meta-analysis in men and women. Behavioral Neuroscience, 124(2), 278287.

Hanoch, Y., Johnson, J. G., \& Wilke, A. (2006). Domain specificity in experimental measures and participant recruitment an application to risk-taking behavior. Psychological Science, 17(4), 300-304.

Harding, C. E. (1981). Social modulation of circulating hormone levels in the male. American Zoologist, 21, 223-232.

Hariri, A. R., Brown, S. M., Williamson, D. E., Flory, J. D., de Wit, H., \& Manuck, S. B. (2006). Preference for immediate over delayed rewards is associated with magnitude of ventral striatal activity. Journal of Neuroscience, 26(51), 13213-13217.

Hartgens, F., \& Kuipers, H. (2004). Effects of androgenic-anabolic steroids in athletes. Sports Medicine, 34, 513-554.

Hermans, E. J., Ramsey, N. F., \& van Honk, J. (2008). Exogenous testosterone enhances responsiveness to social threat in the neural circuitry of social aggression in humans. Biological Psychiatry, 63(3), 263-270.

Hermans, E. J., Bos, P. A., Ossewaarde, L., Ramsey, N. F., Fernandez, G., \& van Honk, J. (2010). Effects of exogenous testosterone on the ventral striatal BOLD response during reward anticipation in healthy women. NeuroImage, 52(1), 277-283.

Hiraishi, K., Sasaki, S., Shikishima, C., \& Ando, J. (2012). The second to fourth digit ratio (2D:4D) in a Japanese twin sample: heritability, prenatal hormone transfer, and association with sexual orientation. Archives of Sexual Behavior, 41(3), 711-724.

Höfer, P., Lanzenberger, R., \& Kasper, S. (2013). Testosterone in the brain: neuroimaging findings and the potential role for neuropsychopharmacology. European Neuropsychopharmacology, 23(2), 79-88.

Hoffman, M., Yoeli, E., \& Jordan, J. (2014). Evidence for an evolutionary basis for sex differences in risk preferences. Mimeo.

Holt, C. A., \& Laury, S. K. (2002). Risk aversion and incentive effects. American Economic Review, 92, 1644-1655.

Hönekopp, J., \& Watson, S. (2010). Meta-analysis of digit ratio shows greater sex difference in the right hand. American Journal of Human Biology, 22(5), 619-630.

Hönekopp, J., \& Watson, S. (2011). Meta-analysis of the relationship between digit-ratio 2D:4D and aggression. Personality and Individual Differences, 51, 381-386.

Hönekopp, J., Manning, J. T., \& Müller, C. (2006). Digit ratio (2D:4D) and physical fitness in males and females: evidence for effects of prenatal androgens on sexually selected traits. Hormones and Behavior, 49, 545-549.

Hönekopp, J., Bartholdt, L., Beier, L., \& Liebert, A. (2007). Second to fourth digit length (2D:4D) and adult sex hormone levels: new data and a meta-analytic review. Psychoneuroendocrinology, 32(4), 313-321. 
Kagel, J. H. (1995). Economic choice theory: an experimental analysis of animal behavior. Cambridge: Cambridge University Press.

Kahneman, D., \& Tversky, A. (1979). Prospect theory: an analysis of decision under risk. Econometrica, $47(2), 263-291$.

Kaufman, J. M., \& Vermeulen, A. (2005). The deceline of androgen leels in elderly men and its clinical and therapeutical implications. Endocrine Reviews, 26(6), 833-876.

Kennerley, S. W., \& Walton, M. E. (2011). Decision making and reward in frontal cortex: complementary evidence from neurophysiological and neuropsychological studies. Behavioral Neuroscience, 125(3), 297.

Killgore, W. D. S. (2007). Effects of sleep-deprivation and morningness-eveningness traits on risk-taking. Psychological Reports, 100, 613-626.

Kuhnen, C. M., \& Chiao, J. Y. (2009). Genetic determinants of financial risk taking. PLoS ONE, 4(2), e4362.

Kuhnen, C. M., \& Knutson, B. (2005). The neural basis of financial risk taking. Neuron, 47(5), 763-770.

Kyriakidis, I., Papaioannidou, P., Pantelidou, V., Kalles, V., \& Gemitzis, K. (2010). Digit ratios and relation to myocardial infarction in Greek men and women. Gender Medicine, 7(6), 628-636.

Lejuez, C. W., Read, J. P., Kahler, C. W., Richards, J. B., Ramsey, S. E., Stuart, G. L., et al. (2002). Evaluation of a behavioral measure of risk taking: the Balloon Analogue Risk Task (BART). Journal of Experimental Psychology: Applied, 8, 75-84.

Levav, J., \& Argo, J. (2010). Physical contact and financial risk taking. Psychological Science, 21, 804-810.

Loewenstein, G., Weber, E., Hsee, C., \& Welch, N. (2001). Risk as feelings. Psychological Bulletin, 127, $267-$ 286.

Lombardo, M. V., Ashwin, E., Auyeung, B., Chakrabarti, B., Taylor, K., Hackett, G., \& Baron-Cohen, S. (2012). Fetal testosterone influences sexually dimorphic gray matter in the human brain. Journal of Neuroscience, 32(2), 674-680.

Lutchmaya, S., Baron-Cohen, S., Raggatt, P., Knickmeyer, R., \& Manning, J. T. (2004). 2nd to 4th digit ratios, fetal testosterone and estradiol. Early Humam Development, 77, 23-28.

Maestripieri, D. (2014). Night owl women are similar to men in their relationship orientation, risk-taking propensities, and cortisol levels: implications for the adaptive significance and evolution of eveningness. Evolutionary Psychology, 12(1), 130-147.

Magnhagen, C. (1991). Predation risk as a cost of reproduction. Trends in Ecology \& Evolution, 6(6), 183186.

Maia, T. V., \& McClelland, J. L. (2004). A reexamination of the evidence for the somatic marker hypothesis: what participants really know in the Iowa gambling task. Proceedings of the National Academy of Sciences of the United States of America, 101(45), 16075-16080.

Malmendier, U., \& Nagel, S. (2011). Depression babies: do macroeconomic experiences affect risk taking? Quarterly Journal of Economics, 126(1), 373-416.

Manning, J. T., \& Taylor, R. P. (2001). Second to fourth digit ratio and male ability in sport: implications for sexual selection in humans. Evolution and Human Behavior, 22, 61-69.

Manning, J. T., Scutt, D., Wilson, J., \& Lewis-Jones, D. I. (1998). The ratio of 2nd to $4^{\text {th }}$ digit length: a predictor of sperm numbers and concentrations of testosterone, lutenizing hormones and oestrogen. Human Reproduction, 13, 3000-3004.

Manning, J. T., Kilduff, L. P., \& Trivers, R. (2013). Digit ratio (2D:4D) in Klinefelter's syndrome. Andrology, 1(1), 94-99.

Manuck, S. B., Marsland, A. L., Flory, J. D., Gorka, A., Ferrell, R. E., \& Hariri, A. R. (2010). Salivary testosterone and a trinucleotide (CAG) length polymorphism in the androgen receptor gene predict amygdala reactivity in men. Psychoneuroendocrinology, 35(1), 94-104.

Mazur, A., \& Booth, A. (1998). Testosterone and dominance in men. Behavioral Brain Sciences, 21(3), 353363.

McClelland, D. C., \& Watson, R. I. (1973). Power motivation and risk-taking behavior. Journal of Personality, 41(1), 121-139.

McHenry, J., Carrier, N., Hull, E., \& Kabbaj, M. (2014). Sex differences in anxiety and depression: role of testosterone. Frontiers in Neuroendocrinology, 35(1), 42-57.

Mehta, P. H., \& Beer, J. (2010). Neural mechanisms of the testosterone-aggression relation: the role of orbitofrontal cortex. Journal of Cognitive Neuroscience, 22(10), 2357-2368.

Mehta, P. H., \& Josephs, R. A. (2006). Testosterone change after losing predicts the decision to compete again. Hormones and Behavior, 50, 684-692.

Muller, M. N., \& Wrangham, R. W. (2004). Dominance, aggression and testosterone in wild chimpanzees: a test of the "challenge hypothesis. Animal Behaviour, 67(1), 113-123.

Nelson, R. J. (2005). Introduction to behavioral endocrinology (3rd ed.). Sunderland: Sinauer. 
Nelson, J.A. (2012). Are women really more risk-averse than men? INET research note 12.

Nicholson, N., Soane, E., Fenton-O’Creevy, M., \& Willman, P. (2005). Personality and domain-specific risk taking. Journal of Risk Research, 8(2), 157-176.

Niederle, M., \& Vesterlund, L. (2007). Do women shy away from competition? Do men compete too much? Quarterly Journal of Economics, 122, 1067-1101.

O'Connell, L. A., \& Hofmann, H. A. (2011). The vertebrate mesolimbic reward system and social behavior network: a comparative synthesis. Journal of Comparative Neurology, 519(18), 3599-3639.

O’Doherty, J. P. (2004). Reward representations and reward-related learning in the human brain: insights from neuroimaging. Current Opinion in Neurobiology, 14(6), 769-776.

Ökten, A., Kalyoncu, M., \& Yariș, N. (2002). The ratio of second- and fourth-digit lengths and congenital adrenal hyperplasia due to 21-hydroxylase deficiency. Early Human Development, 70(1-2), 47-54.

Op de Macks, Z. A., Moor, B. G., Overgaauw, S., Guroglu, B., Dahl, R. E., \& Crone, E. A. (2011). Testosterone levels correspond with increased ventral striatum activation in response to monetary rewards in adolescents. Developmental Cognitive Neuroscience, 1(4), 506-516.

Packard, M. G., Cornell, A. H., \& Alexander, G. M. (1997). Rewarding affective properties of intra-nucleus accumbens injections of testosterone. Behavioral Neuroscience, 111(1), 219.

Packard, M. G., Schroeder, J. P., \& Alexander, G. M. (1998). Expression of testosterone conditioned place preference is blocked by peripheral or intra-accumbens injection of $\alpha$-flupenthixol. Hormones and Behavior, 34(1), 39-47.

Padoa-Schioppa, C., \& Assad, J. A. (2006). Neurons in the orbitofrontal cortex encode economic value. Nature, 441(7090), 223-226.

Pearson, M., \& Schipper, B. C. (2012). The visible hand: finger ratio (2D:4D) and competitive bidding. Experimental Economics, 15, 510-529.

Pfannkuche, K. A., Bouma, A., \& Groothuis, T. G. G. (2009). Does testosterone affect lateralization of brain and behaviour? A meta-analysis in humans and other animal species. Philosophical Transactions of the Royal Society B, 364, 929-942.

Platt, M. L., \& Huettel, S. A. (2008). Risky business: the neuroeconomics of decision making under uncertainty. Nature Neuroscience, 11, 398-403.

PricewaterhouseCoopers. (2010). Playing to win: the outlook for the global casino and online gambling market to 2014. PricewaterhouseCoopers.

Rahman, F., \& Christian, H. C. (2007). Non-classical actions of testosterone: an update. Trends in Endocrinology and Metabolism, 18(10), 371-378.

Randler, C., Ebenhoh, N., Fischer, A., Hochel, S., Schroff, C., Christin Stoll, J., \& Vollmer, C. (2012). Chronotype but not sleep length is related to salivary testosterone in young adult men. Psychoneuroendocrinology, 37(10), 1740-1744.

Ranehill, E., Dreber, A., Johannesson, M., Leiberg, S., Sul, S., \& Weber, R.A. (2014). Assessing the robustness of power posing: no effect on hormones and risk tolerance in a large sample of men and women. Psychological Science.

Rivas, M. P., Moreira, L. M. A., Santo, L. D. E., Marques, A. C. S. S., El-Hani, C. N., \& Toralles, M. B. P. (2014). New studies of second and fourth digit ratio as a morphogenetic trait in subjects with congenital adrenal hyperplasia. American Journal of Human Biology, 26(4), 559-561.

Roberti, J. W. (2004). A review of behavioral and biological correlates of sensation seeking. Journal of Research in Personality, 38, 256-279.

Robson, A. (1996). A biological basis for expected and non-expected utility. Journal of Economic Theory, 68, $397-424$

Robson, A. (2001). Why would nature give individuals utility functions? Journal of Political Economy, 109, 900-914.

Rogers, R. D., Owen, A. M., Middleton, H. C., Williams, E. J., Pickard, J. D., Sahakian, B. J., \& Robbins, T. W. (1999). Choosing between small, likely rewards and large, unlikely rewards activates inferior and orbital prefrontal cortex. Journal of Neuroscience, 19(20), 9029-9038.

Ronay, R., \& von Hippel, W. (2010a). Power, testosterone, and risk taking. Journal of Behavioral Decision Making, 23, 473-482.

Ronay, R., \& von Hippel, W. (2010b). The presence of an attractive woman elevates testosterone and physical risk taking in young men. Social Psychology and Personality Science, 1, 57-64.

Roney, J. R., Lukaszewski, A. W., \& Simmons, Z. L. (2007). Rapid endocrine responses of young men to social interactions with young women. Hormones and Behavior, 52, 326-333.

Rudebeck, P. H., Walton, M. E., Smyth, A. N., Bannerman, D. M., \& Rushworth, M. F. (2006). Separate neural pathways process different decision costs. Nature Neuroscience, 9(9), 1161-1168.

Samuelson, L., \& Swinkels, J. (2006). Information, evolution and utility. Theoretical Economics, 1, 119-142. 
Sapienza, P., Zingales, L., \& Maestripieri, D. (2009). Gender differences in financial risk aversion and career choices are affected by testosterone. Proceedings of the National Academy of Sciences, 106, 15268-15273.

Schipper, B.C. (2012). Sex hormones and choice under risk. Mimeo.

Schipper, B.C. (2014). Sex hormones and competitive bidding. Management Science.

Schultheiss, O. C., Campbell, K. L., \& McClelland, D. C. (1999). Implicit power motivation moderates men's testosterone responses to imagined and real dominance success. Hormones and Behavior, 36, 234-241.

Schulz, K. M., Molenda-Figueira, H. A., \& Sisk, C. L. (2009). Back to the future: the organizationalactivational hypothesis adapted to puberty and adolescence. Hormones and Behavior, 55(5), 597-604.

Sellers, J. G., Mehl, M. R., \& Josephs, R. A. (2007). Hormones and personality: testosterone as a marker of individual differences. Journal of Research in Personality, 41(1), 126-138.

Seo, H., Kim, K. Y., \& Rho, J. (2010). Is the index finger and ring finger ratio (2D:4D) reliable predictor of semen quality? Korean Journal of Urology, 51(3), 208-211.

Shoemaker, P. J. (1990). Are risk-attitudes related across domains and response modes? Management Science, 36(12), 1451-1463.

Sluming, V. A., \& Manning, J. T. (2000). Second to fourth digit ratio in elite musicians: evidence for musical ability as an honest signal of male fitness. Evolution and Human Behavior, 21, 1-9.

Stanton, S.J. (2011). The essential implications of gender in human behavioral endocrinology studies. Frontiers in Behavioral Neuroscience, 5(9), doi: 10.3389/fnbeh.2011.00009.

Stanton, S. J., Liening, S. H., \& Schultheiss, O. C. (2011a). Testosterone is positively associated with risk taking in the Iowa gambling task. Hormones and Behavior, 59(2), 252-256.

Stanton, S. J., Mullette-Gillman, O., McLaurin, R., Kuhn, C., LaBar, K., Platt, M., \& Huettel, S. (2011b). Low- and high-testosterone individuals exhibit decreased aversion to economic risk. Psychological Science, 22, 447-453.

Starmer, C. (2000). Developments in non-expected utility theory: the hunt for a descriptive theory of choice under risk. Journal of Economic Literature, 38(2), 332-382.

Stenstrom, E., Saad, G., Nepomuceon, M. V., \& Mendenhall, Z. (2011). Testosterone and domain-specific risk: Digit ratios (2D:4D and rel2) as predictors of recreational, financial, and social risk-taking behaviors. Personality and Individual Differences, 51, 412-416.

Sytsma, T. (2014). Handling risk: testosterone and risk preference evidence from Dhaka. Bangladesh: Mimeo.

Tremblay, L., \& Schultz, W. (1999). Relative reward preference in primate orbitofrontal cortex. Nature, 398(6729), 704-708.

Triemstra, J. L., Sato, S. M., \& Wood, R. I. (2008). Testosterone and nucleus accumbens dopamine in the male Syrian hamster. Psychoneuroendocrinology, 33(3), 386-394.

Tversky, A., \& Kahneman, D. (1986). Rational choice and the framing of decisions. Journal of Business, S251-S278.

Tversky, A., Slovic, P., \& Kahneman, D. (1990). The causes of preference reversal. American Economic Review, 80(1), 204-217.

Van Anders, S. M., Vernon, P. A., \& Wilbur, C. J. (2006). Finger-length ratios show evidence of prenatal hormone-transfer between opposite-sex twins. Hormones and Behavior, 49(3), 315-319.

van der Meij, L., Almela, M., Buunk, A. P., Fawcett, T. W., \& Salvador, A. (2012). Men with elevated testosterone levels show more affiliative behaviours during interactions with women. Proceedings of the Royal Society of London B: Biological Sciences, 279, 202-208.

van Honk, J., Tuiten, A., \& Verbaten, R. (1999). Correlations among salivary testosterone, mood, and selective attention to threat in humans. Hormones and Behavior, 36, 17-24.

van Honk, J., Schutter, D. J. L. G., Hermans, E. J., Putnam, P., Tuiten, A., \& Koppeschaar, H. (2004). Testosterone shifts the balance between sensitivity for punishment and reward in healthy young women. Psychoneuroendocrinology, 29(7), 937-943.

van Wingen, G. A., Zylicz, S. A., Pieters, S., Mattern, C., Verkes, R. J., Buitelaar, J. K., \& Fernandez, G. (2009). Testosterone increases amygdala reactivity in middle-aged women to a young adulthood level. Neuropsychopharmacology, 34, 539-547.

van Wingen, G., Mattern, C., Verkes, R. J., Buitelaar, J., \& Fernández, G. (2010). Testosterone reduces amygdala-orbitofrontal cortex coupling. Psychoneuroendocrinology, 35(1), 105-113.

Ventura, T., Gomes, M. C., Pita, A., Neto, M. T., \& Taylor, A. (2013). Digit ratio (2D:4D) in newborns: influences of prenatal testosterone and maternal environment. Early Human Development, 89(2), 107-112.

Verdonck, A., Gaethofs, M., Carels, C., et al. (1999). Effect of low-dose testosterone treatment on craniofacial growth in boys with delayed puberty. European Journal of Orthodontics, 21, 137-143.

Vermeersch, H., T’Sjoen, G., Kaufman, J. M., Vincke, J., \& Van Houtte, M. (2010). Testosterone, androgen receptor gene CAG repeat length, mood and behaviour in adolescent males. European Journal of Endocrinology, 163, 319-328. 
White, R. E., Thornhill, S., \& Hampson, E. (2006). Entrepreneurs and evolutionary biology: the relationship between testosterone and new venture creation. Organizational Behavior and Human Decision Processes, 100, 21-34.

Wingfield, J. C., Hegner, R. E., Dufty, A. M., \& Ball, G. F. (1990). The "challenge hypothesis": theoretical implications for patterns of testosterone secretion, mating systems, breeding strategies. American Naturalist, 136, 829-846.

Worthman, C. M., \& Konner, M. J. (1987). Testosterone levels change with subsistence hunting effort in !Kung San men. Psychoneuroendocrinology, 12, 449-458.

Zethraeus, N., Kocoska-Maras, L., Ellingsen, T., von Schoultz, B., Lindén Hirschberg, A., \& Johannesson, M. (2009). A randomized trial of the effect of estrogen and testosterone on economic behavior. Proceedings of the National Academy of Sciences, 106, 6535-6538.

Zheng, Z., \& Cohn, M. J. (2011). Developmental basis of sexually dimorphic digit ratios. Proceedings of the National Academy of Sciences, 108(39), 16289-16294.

Zuckerman, M., \& Kuhlman, D. M. (2000). Personality and risk-taking: common bisocial factors. Journal of Personality, 68(6), 999-1029. 